\title{
Favorable effect of the combination of vinorelbine and dihydropyrimidine dehydrogenase-inhibitory fluoropyrimidine in $E G F R$-mutated lung adenocarcinoma: Retrospective and in vitro studies
}

\author{
HIROKI IZUMI ${ }^{1}$, HIROKAZU TOUGE ${ }^{1}$, TADASHI IGISHI ${ }^{1}$, HARUHIKO MAKINO $^{1}$, \\ SHIZUKA NISHII-ITO ${ }^{1}$, MIYAKO TAKATA ${ }^{1}$, HIROFUMI NAKAZAKI ${ }^{1}$, YASUTO UEDA ${ }^{1}$, \\ SHINGO MATSUMOTO ${ }^{1}$, MASAHIRO KODANI ${ }^{1}$, JUN KURAI ${ }^{1}$, KENICHI TAKEDA ${ }^{1}$, \\ TOMOHIRO SAKAMOTO ${ }^{1}$, MASAAKI YANAI ${ }^{1}$, NATSUMI TANAKA ${ }^{1}$, \\ CHAITANYA S. NIRODI ${ }^{2}$ and EIJI SHIMIZU ${ }^{1}$ \\ ${ }^{1}$ Division of Medical Oncology and Molecular Respirology, Faculty of Medicine, \\ Tottori University, Yonago, Tottori 683-8504, Japan; ${ }^{2}$ Department of Oncologic Sciences, \\ Mitchell Cancer Institute, University of South Alabama, Mobile, AL 36604, USA
}

Received October 10, 2014; Accepted November 25, 2014

DOI: $10.3892 /$ ijo.2015.2815

\begin{abstract}
Although cytotoxic chemotherapy is essential in epidermal growth factor receptor $(E G F R)$-mutated non-small cell lung cancer (NSCLC), it is unclear which regimen is most effective. We retrospectively compared the efficacy of standard platinum-based chemotherapy with that of combination chemotherapy using vinorelbine (VNR) plus dihydropyrimidine dehydrogenase-inhibitory fluoropyrimidine (DIF) in EGFR-mutated lung adenocarcinomas, and we investigated a potential mechanism by which the combination chemotherapy of VNR + DIF was favorable in the treatment of $E G F R$-mutated lung adenocarcinoma in vitro. In our retrospective analysis, the response rate and disease control rate afforded by the VNR + DIF treatment tended to be better than those by platinum-based chemotherapy, and the progression-free survival of the $24 \mathrm{VNR}+$ DIF-treated patients was significantly longer than that of the 15 platinum-based chemotherapy patients. In EGFR-mutated PC9 cells, VNR induced EGFR dephosphorylation at a clinically achievable concentration. 1BR3-LR cells, a line of fibroblast cells transfected with a mutant $E G F R$ construct, were completely resistant to gefitinib in the medium containing $10 \%$ fetal bovine serum (FBS), whereas the sensitivity of
\end{abstract}

Correspondence to: Dr Tadashi Igishi, Division of Medical Oncology and Molecular Respirology, Faculty of Medicine, Tottori University, 36-1 Nishi-machi, Yonago 683-8504, Japan

E-mail: igishi@med.tottori-u.ac.jp

Key words: vinorelbine, dihydropyrimidine dehydrogenase-inhibitory fluoropyrimidine, 5-fluorouracil, epidermal growth factor receptor, lung adenocarcinoma these cells to gefitinib was increased in $0.5 \%$ FBS-containing medium. Similarly, the sensitivity of 1BR3-LR cells to VNR was increased when they were cultured in low-serum condition. In addition, sodium orthovanadate $\left(\mathrm{Na}_{3} \mathrm{VO}_{4}\right)$ inhibited the EGFR dephosphorylation induced by VNR or gefitinib and suppressed the cell growth inhibition by these agents in PC9 cells. VNR and gefitinib showed synergistic cell growth inhibition in combination with 5-fluorouracil (5-FU) in PC9 cells. We propose that the EGFR dephosphorylation induced by VNR is related to cell growth inhibitory activity of VNR, and that this is one of the mechanisms of the synergistic effect of $\mathrm{VNR}+5-\mathrm{FU}$ in EGFR-mutated lung cancer cells. In conclusion, the combination chemotherapy of VNR + DIF may be a promising treatment for NSCLC patients with EGFR mutations.

\section{Introduction}

Lung cancer is the leading cause of cancer-related death worldwide. More than $80 \%$ of lung cancers are non-small cell lung cancers (NSCLCs), and lung adenocarcinoma is the most common type of NSCLC. The median survival of patients with metastatic NSCLC treated with cytotoxic chemotherapy agents is $10-12$ months $(1,2)$.

Epidermal growth factor receptor (EGFR), a member of the family of growth factor receptor tyrosine kinases, is expressed in a variety of solid cancers. EGFR somatic mutations were identified in 5-40\% of NSCLCs, and is especially common in never-smokers, women, Asians, and patients with adenocarcinoma (3-6). NSCLCs harboring-activated EGFR mutations are addicted to EGFR signaling, and treatment with small-molecule EGFR-tyrosine kinase inhibitors (TKIs) such as gefitinib and erlotinib demonstrated dramatic responses to lung adenocarcinomas with $E G F R$ mutations $(7,8)$. However, almost all lung adenocarcinoma patients with $E G F R$ mutations 
who respond to EGFR-TKIs ultimately develop resistance to these agents. Therefore, to prolong the survival time of advanced NSCLC patients with EGFR mutations, conventional cytotoxic chemotherapy is necessary regardless of whether it is administered before or after treatment with EGFR-TKIs.

At present, the combination of platinum with one of several chemotherapeutic agents [docetaxel, paclitaxel, gemcitabine, vinorelbine (VNR), irinotecan, pemetrexed or FT-5-chloro-2,4-dihydroxypyridine-potassium oxonate (S-1)] is considered a standard chemotherapy for advanced NSCLC $(1,2,9,10)$. However, non-platinum combinations of third-generation drugs such as gemcitabine + VNR have less toxicity and almost equivalent efficacy compared to platinum-based chemotherapy (11). Therefore, non-platinum combination chemotherapy can be an option as a first-line treatment, even in patients with advanced NSCLC harboring EGFR mutations.

VNR, which is widely used to treat solid tumors such as NSCLC and breast cancer, is a semisynthetic vinca-alkaloid derived from vinblastine. This chemotherapeutic agent is one of the standard treatment agents for elderly patients with NSCLC (12), and, in combination with cisplatin, VNR is the only third-generation drug that demonstrated a consistent improvement of survival in the adjuvant setting of resected NSCLC (13-15).

UFT is an oral anticancer agent combining tegafur (FT) and uracil at a molar ratio of 1:4. FT is a prodrug of 5-fluorouracil (5-FU), and uracil is a competitive and reversible inhibitor of dihydropyrimidine dehydrogenase (DPD), the rate-limiting enzyme responsible for the catabolism of 5-FU. $\mathrm{S}-1$ is a novel oral fluorouracil antitumor drug that combines FT, 5-chloro-2,4-dihydroxypyridine (which inhibits DPD activity), and potassium oxonate (which reduces gastrointestinal toxicity). UFT and S-1 are referred to as dehydrogenase-inhibitory fluoropyrimidine (DIF).

UFT is effective in prolonging the survival of patients with NSCLC after surgical resection $(16,17)$. In a recent phase III trial, the combination chemotherapy of S-1 with carboplatin was not inferior in terms of overall survival (OS) compared with a standard chemotherapy, carboplatin and paclitaxel, for patients with advanced NSCLC (9). These results suggest the potential of DIF as a chemotherapeutic agent for advanced NSCLC.

We reported the schedule-dependent synergistic effect of VNR and subsequent 5-FU or UFT on NSCLC in vitro and in an animal model (18). Based on these preclinical data, we conducted two phase II studies of VNR + DIF, under which VNR was infused on days 1 and 8 , and $600 \mathrm{mg} /$ day UFT or $80 \mathrm{mg} / \mathrm{m}^{2} /$ day S-1 was administered daily from day 2 to 6 and from day 9 to 13 in a 3 -week cycle. The combination therapy of VNR + UFT was shown to be feasible and active in the treatment of elderly patients with advanced NSCLC (19). Promising results were also observed in unselected advanced NSCLC patients treated with the combination of $\mathrm{VNR}+\mathrm{S}-1$ (20).

In the process of clinical trials and clinical practice applying the combination treatment of VNR + DIF for advanced NSCLC, we noticed that patients exhibiting long-term stable disease tended to harbor $E G F R$ mutations. This finding raised a hypothesis that the combination treatment of VNR + DIF may be specifically effective in NSCLC patients with EGFR mutations.

In the present study, we retrospectively compared the efficacy of the combination treatment of VNR + DIF with that of the standard platinum-based chemotherapy in patients with lung adenocarcinoma harboring EGFR mutations. We also sought to identify the mechanism by which the combination chemotherapy of VNR + DIF was more favorable than platinum-based chemotherapy in NSCLC harboring EGFR mutations in vitro.

\section{Materials and methods}

Comparison of the effects of chemotherapies. We retrospectively reviewed 39 lung adenocarcinoma patients harboring EGFR mutations who were diagnosed from November, 2004 to March, 2013 at Tottori University Hospital in Yonago, Japan and who received the combination therapy of VNR + DIF or platinum-based chemotherapy for the first cytotoxic chemotherapy. The presence of EGFR mutation was evaluated by the polymerase chain reaction (PCR)-invader method (BML, Inc., Tokyo, Japan). EGFR mutation analyses were not performed in four cases. These patients achieved long-term progression-free survival (PFS) times of $>6$ months with gefitinib treatment. The PFS was $<6$ months in $>95 \%$ of the EGFR mutation-negative patients (21). Thus, we considered these four patients as $E G F R$ mutation-positive cases.

The differences between the two groups were compared by the Mann-Whitney test and $\chi^{2}$ or Fisher's exact test for numerical and categorized data, respectively. Tumor response was evaluated according to the Response Evaluation Criteria in Solid Tumors (RECIST) (22). The OS and PFS times following the first-line cytotoxic chemotherapy was assessed using the Kaplan-Meier method and compared by the log-rank test. $\mathrm{P}<0.05$ was considered significant.

Chemicals and reagents. VNR (Kyowa Hakko Kirin Co., Ltd., Tokyo, Japan) was dissolved in distilled water and stored at $-20^{\circ} \mathrm{C}$. A stock solution of cisplatin (CDDP) (Nippon Kayaku Co., Ltd., Tokyo, Japan) was reconstituted with water, diluted in $0.9 \%$ sodium chloride solution, and stored at $-20^{\circ} \mathrm{C}$. Gefitinib(AstraZeneca,Cheshire,UK)and 5-FU(KyowaHakko Kirin Co., Ltd.) were dissolved in dimethyl sulfoxide and stored at $-20^{\circ} \mathrm{C}$. 3-(4,5-Dimethylhiazol-2-yl)-2,5-diphenyltetrazolium bromide (MTT) (Wako Pure Chemical Industries, Ltd., Osaka, Japan) was dissolved in phosphate-buffered saline (PBS) and stored at $-20^{\circ} \mathrm{C}$.

Cell lines and cultures. The human NSCLC cell line PC9, which harbors an EGFR exon 19 deletion mutation $(\triangle E 746-A 750)(23)$ was obtained from the RIKEN BioResource Center (Ibaraki, Japan). The fibroblast cell line 1BR3, stably transfected with a mutant EGFR construct with an L858R replacement in exon 21 (1BR3-LR), was a generous gift from Dr David J. Chen (24). The PC9 cells were maintained in RPMI-1640 medium supplemented with $10 \%$ fetal bovine serum (FBS) and antibiotics $(100 \mathrm{U} / \mathrm{ml}$ penicillin and $100 \mu \mathrm{g} / \mathrm{ml}$ streptomycin). 1BR3-LR cells were maintained in MEM- $\alpha$ medium supplemented with $10 \%$ FBS and antibiotics (100 U/ml penicillin, $100 \mu \mathrm{g} / \mathrm{ml}$ streptomycin, and $2 \mu \mathrm{g} / \mathrm{ml}$ 
blasticidin). These cells were grown in a humidified atmosphere of $5 \% \mathrm{CO}_{2} / 95 \%$ air at $37^{\circ} \mathrm{C}$.

MTT assay. The cell growth inhibition by chemotherapeutic agents was determined by an MTT assay. Cells counted with a hematocytometer were plated in 96-well flat-bottom multiplates (Nalge Nunc International Corp., Rochester, NY, USA) in $100 \mu \mathrm{l}$ of medium and incubated overnight to permit cell attachment. The medium was then removed from each well and replaced with $100 \mu \mathrm{l}$ medium containing the drugs for the indicated time. After $72 \mathrm{~h}, 10 \mu \mathrm{g}$ of MTT in $10 \mu \mathrm{l}$ PBS was added to each well, and incubation was continued for an additional $4 \mathrm{~h}$. Thereafter, $100 \mu \mathrm{l}$ of $0.04 \mathrm{~N} \mathrm{HCl}$ in 2-propanol was added, and the multiplates were incubated overnight to solubilize the MTT formazan crystal. The absorbance of each well was measured at $570 \mathrm{~nm}$ wavelength (reference $650 \mathrm{~nm}$ ) using a Tecan Sunrise scanning multiwell spectrometer (Tecan Japan Co., Ltd., Kanagawa, Japan). Each experiment was performed in triplicate for each drug concentration and was independently performed three times.

Immunoprecipitation and western blot analysis. Cells were incubated in 6-well tissue culture plates overnight and washed with ice-cold PBS and lysed in lysis buffer [1\% NP-40, $0.25 \%$ sodium deoxycholate, $150 \mathrm{mM} \mathrm{NaCl}, \mathrm{pH} 7.4,50 \mathrm{mM}$ Tris-HCl, $1 \mathrm{mM}$ EDTA, $1 \mathrm{mM} \mathrm{NaF}, 1 \mathrm{mM}$ sodium orthovanadate $\left(\mathrm{Na}_{3} \mathrm{VO}_{4}\right)$ ] including $1 \mathrm{mM}$ phenylmethylsulfonyl fluoride, $1 \mu \mathrm{g} / \mathrm{ml}$ leupeptin, $1 \mu \mathrm{g} / \mathrm{ml}$ aprotinin, and $1 \mu \mathrm{g} / \mathrm{ml}$ pepstatin. After $5 \mathrm{~min}$ on ice, lysates were centrifuged at $13,000 \mathrm{x} \mathrm{g}$ for $10 \mathrm{~min}$ at $4^{\circ} \mathrm{C}$, and the supernatant was then collected. Protein was measured using the Bio-Rad Protein Assay reagent (Bio-Rad Laboratories, Hercules, CA, USA), and protein lysates containing $20 \mu \mathrm{g}$ of total cellular protein or immunoprecipitates with the indicated antibodies were subjected to discontinuous sodium dodecyl sulfate-polyacrylamide gel electrophoresis (SDS-PAGE).

Proteins were electrotransferred to a polyvinylidene fluoride (PVDF) membrane (GE Healthcare Japan, Tokyo, Japan) for $60 \mathrm{~min}$ at $4^{\circ} \mathrm{C}$ at $100 \mathrm{~V}$. Non-specific binding was blocked by incubation with $5 \%$ non-fat milk in Tris-buffered saline containing $0.1 \%$ Tween-20 (TBST) for $1 \mathrm{~h}$ at room temperature. After blocking, the membrane was incubated in primary antibody (1X PBST containing 1\% milk, 1:2,000) overnight at $4^{\circ} \mathrm{C}$. The membrane was then washed three times with PBST. The immunoblots were incubated for $1 \mathrm{~h}$ in a 1:10,000 dilution of goat anti-rabbit or anti-mouse IgG coupled with horseradish peroxidase as a secondary antibody (GE Healthcare Japan) in TBST containing $1 \%$ milk.

Finally, each protein was detected using an enhanced chemiluminescence detection system (ECL prime) and captured with an ImageQuant LAS 400 (both from GE Healthcare Japan). The antibody against EGFR was purchased from Santa Cruz Biotechnology, Inc. (Santa Cruz, CA, USA). Anti-phosphotyrosine antibody (4G10) was purchased from Merck Millipore (Darmstadt, Germany), and anti- $\beta$-actin antibody was purchased from Sigma-Aldrich Japan (Tokyo, Japan).

Assessment of combination effect. A combination index (CI) was calculated using the Chou-Talalay method (25) and used to evaluate the combination effect of the two drugs. The CI quantitatively depicts synergism $(\mathrm{CI}<1)$, addictive effect $(\mathrm{CI}=1)$, and antagonism $(\mathrm{CI}>1)$.

\section{Results}

The characteristics of patients and efficacy of VNR + DIF and platinum-based chemotherapy. A total of 39 patients were included in this retrospective study. The ages of the 39 patients ranged from 35 to 84 years (median age, 65 years), with 16 males $(41.0 \%)$ and 23 females (59\%). All tumors were adenocarcinomas, and 31 patients had stage IV disease (79.5\%). Seven patients received gefitinib prior to cytotoxic chemotherapy.

At the first cytotoxic chemotherapy, 24 patients received VNR + DIF chemotherapy (VNR + UFT, n=5; VNR + S-1, $\mathrm{n}=19)$ and the other 15 patients received platinum-based chemotherapy. Of the 15 patients in the platinum group, eight patients received CDDP-based chemotherapy (CDDP + gemcitabine, $\mathrm{n}=4$; CDDP + docetaxel, $\mathrm{n}=4$ ), and the seven others received carboplatin-based chemotherapy (carboplatin + paclitaxel, $n=5$; carboplatin + pemetrexed, $n=1$; carboplatin + gemcitabine, $n=1$ ).

Table I shows the patient characteristics according to the first-line chemotherapy regimen (VNR + DIF vs. platinum). There was no significant difference between the two regimen groups with regard to age, gender, disease stage, smoking status, EGFR mutation type, Eastern Cooperative Oncology Group (ECOG) performance status (PS), and chemotherapy line. As a later line of cytotoxic chemotherapy, seven (29.2\%) patients in the VNR + DIF group received platinum-based chemotherapy, and four (26.7\%) patents in the platinum group received VNR + DIF treatment.

Both the objective response rate (ORR) and the disease control rate (DCR) of the VNR + DIF patients were favorable compared with those of the platinum group, although the differences were not significant (54.2 vs. $42.9 \%, \mathrm{p}=0.74$ and 87.5 vs. $71.4 \%$, p=0.39; Table II). Fig. 1 shows the Kaplan-Meier curves for PFS in the VNR + DIF and platinum groups. The median PFS of the VNR + DIF group was significantly longer than that of the platinum group ( 7.4 vs. 3.7 months, $\mathrm{p}=0.02$ ). The median OS was not significantly different between the two groups (36.6 vs. 35.4 months, $\mathrm{p}=0.34$; Table II).

The cell growth inhibition and effect of VNR, CDDP and 5-FU on EGFR phosphorylation in PC9 cells. Based on the results of the retrospective study, we speculated that VNR or DIF may have an effect on EGFR activity. To address this speculation, we performed in vitro experiments using PC9 cells harboring an active form of EGFR mutation.

We first evaluated the sensitivity of PC9 cells to VNR, 5-FU, and CDDP. The half-life of VNR in plasma after intravenous injection is $20 \mathrm{~h}(26)$, and CDDP is almost completely eliminated within $24 \mathrm{~h}$ from plasma (27). In previous studies, DIF was orally administered to patients for 5 days in the combination of VNR + DIF $(19,20)$, and the 5-FU concentration in plasma stayed roughly constant during an oral intake of DIF $(28,29)$. We therefore exposed PC9 cells to VNR, CDDP and 5-FU for 24, 24 and $72 \mathrm{~h}$, respectively, and $72 \mathrm{~h}$ after the start of drug exposure, we performed an MTT assay to evaluate the inhibition of cell proliferation. The concentration 
Table I. Characteristics of the 39 lung adenocarcinoma patients harboring EGFR mutations.

$\begin{array}{ccc}\substack{\text { VNR + DIF } \\(\mathrm{n}=24)} & \begin{array}{c}\text { Platinum } \\ (\mathrm{n}=15)\end{array} & \text { P-value } \\ & & \end{array}$

\section{Age (years)}

Median (range)

$66.5(50-84) \quad 64(35-74)$

Sex

$\begin{array}{lll}\text { Male } & 10 & 6 \\ \text { Female } & 14 & 9\end{array}$

Disease stage

IIIA
IIIB
IV

Recurrence

Histology

Adenocarcinoma

Smoking status

Current
Former
Never

EGFR mutation type

Exon 19 deletion
Exon 21 point mutation
Minor mutation
Unknown

$3 \quad 3$$$
54
$$$$
16 \quad 8
$$

Performance status

$\begin{array}{ll}0 & 1 \\ 1 & 1 \\ 2 & \end{array}$

Chemotherapy line

$\begin{array}{lrr}\text { First-line } & 20 & 12 \\ \text { Second-line } & 4 & 3 \\ \text { (gefitinib as first-line) } & & \end{array}$

${ }^{\mathrm{a}}$ Mann-Whitney test, ${ }^{\mathrm{b}}$ Fisher's exact test and ${ }^{\mathrm{c}} \chi^{2}$ test. EGFR, epidermal growth factor receptor; VNR, vinorelbine; DIF, dihydropyrimidine dehydrogenase-inhibitory fluoropyrimidine.

of VNR producing a $50 \%$ inhibition of cell growth $\left(\mathrm{IC}_{50}\right)$ was $8.1 \mathrm{nM}$, that of CDDP was $0.59 \mu \mathrm{M}$, and that of 5-FU was $13.8 \mu \mathrm{M}$ (Fig. 2), and these are clinically achievable concentrations (26-29).

We evaluated the phosphorylation of EGFR after the treatment with each drug at the concentrations up to 2 -fold higher than the $\mathrm{IC}_{50}$. After the treatment with a $10 \mathrm{nM}$ or higher concentration of VNR for $24 \mathrm{~h}$, the phosphorylation of EGFR was clearly decreased. In the PC9 cells, this EGFR dephosphorylation induced by VNR appeared 12-24 h after
Table II. Comparison of efficacy parameters between the combination of VNR + DIF and platinum-based chemotherapy.

\begin{tabular}{lccc}
\hline $\begin{array}{l}\text { Confidence } \\
\text { interval (95\%) }\end{array}$ & $\begin{array}{c}\text { VNR + DIF } \\
(\mathrm{n}=24)\end{array}$ & $\begin{array}{c}\text { Platinum } \\
(\mathrm{n}=15)\end{array}$ & P-value \\
\hline ORR & $54.2(32.0-76.4)$ & $42.9(29.6-56.1)$ & $0.74^{\mathrm{a}}$ \\
DCR & $87.5(80.7-94.3)$ & $71.4(59.4-83.5)$ & $0.39^{\mathrm{a}}$ \\
mPFS (months) & $7.4(6.2-8.7)$ & $3.7(2.9-4.6)$ & $0.02^{\mathrm{b}}$ \\
mOS (months) & $36.6(27.2-46.0)$ & $35.4(31.0-39.7)$ & $0.34^{\mathrm{b}}$ \\
\hline
\end{tabular}

${ }^{a}$ Fisher's exact test and ${ }^{b} \log$-rank test. VNR, vinorelbine; DIF, dihydropyrimidine dehydrogenase-inhibitory fluoropyrimidine; ORR, objective response rate; DCR, disease control rate; mPFS, median progression-free survival; mOS, median overall survival.

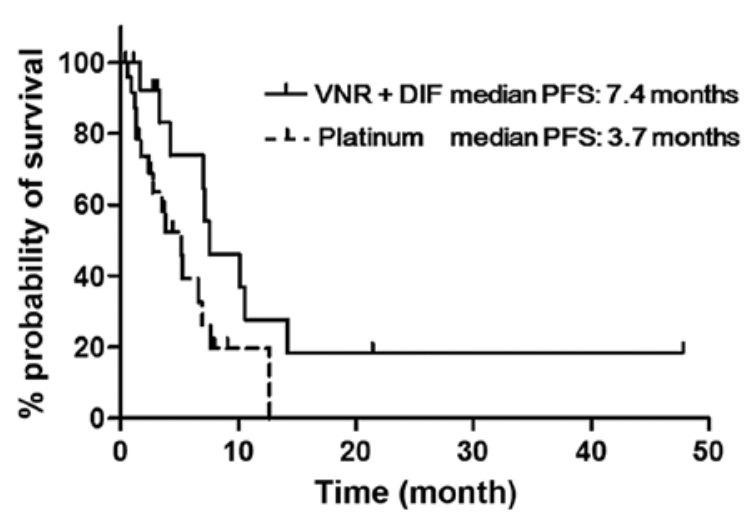

Figure 1. Kaplan-Meier curves of the progression-free survival (PFS) of the patients who received vinorelbine (VNR) + dehydrogenase-inhibitory fluoropyrimidine (DIF) chemotherapy $(n=24)$ or platinum-based chemotherapy $(n=15)$.

the start of the exposure to $20 \mathrm{nM}$ VNR (Fig. 3A), whereas such dephosphorylation of EGFR was not detected in the 24-h treatment with 5-FU or CDDP at the concentrations tested (Fig. 3B and C).

The cell growth inhibition and effects of gefitinib, VNR, CDDP and 5-FU on EGFR phosphorylation in 1BR3-LR cells. To elucidate whether the suppression of EGFR phosphorylation induced by VNR functions as an anti-proliferative mechanism of VNR, we used 1BR3 cells (in which EGFR is not expressed), stably transfected with the L858R mutant EGFR (1BR3-LR).

We determined the effects of gefitinib, VNR, CDDP and 5-FU on EGFR phosphorylation in 1BR3-LR cells. As shown in Fig. 4A, the treatment with $10 \mathrm{nM}$ VNR for $24 \mathrm{~h}$ suppressed EGFR phosphorylation as well as gefitinib did, a selective EGFR-TKI in 1BR3-LR cells. Similar to the PC9 cells, neither CDDP nor 5-FU induced the dephosphorylation of EGFR.

We evaluated the cell growth inhibition by these drugs in 1BR3-LR cells. In 1BR3-LR cells cultured in 10\% FBS-containing medium, gefitinib slightly promoted cell growth, although it effectively suppressed EGFR phosphorylation. Gefitinib inhibited the cell growth concentration dependently in the medium containing $0.5 \%$ FBS (Fig. 4B), indicating that 

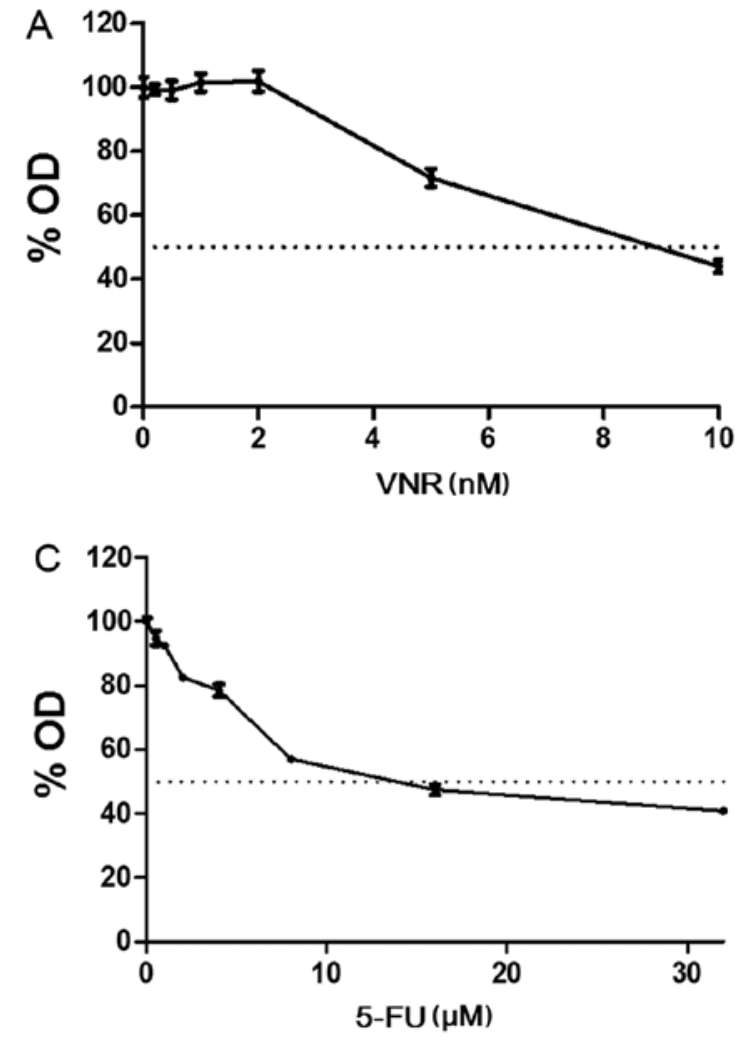

A
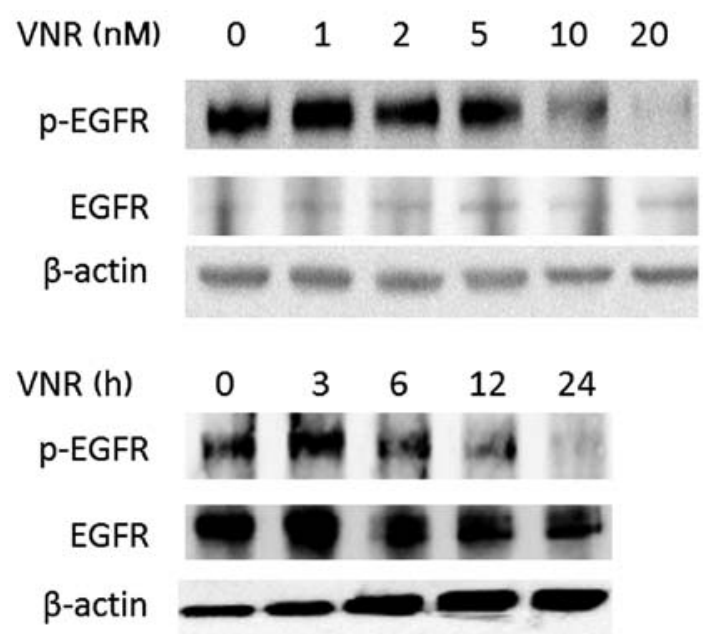

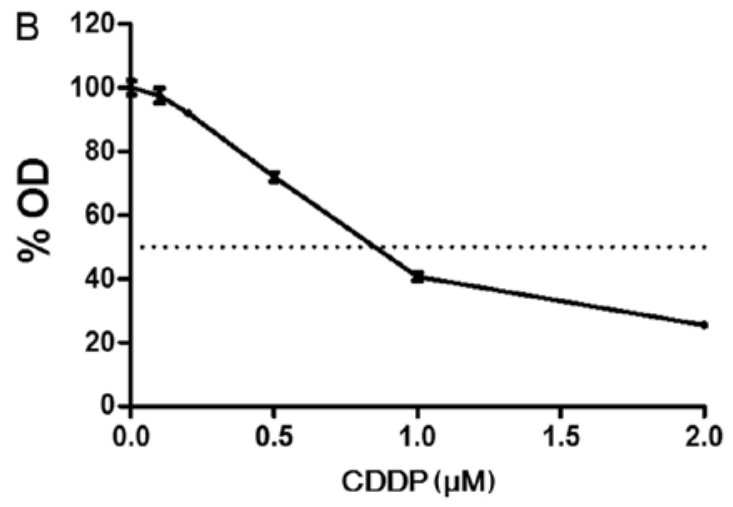

Figure 2. Sensitivity of PC9 cells to vinorelbine (VNR), cisplatin (CDDP), and 5-fluorouracil (5-FU). (A-C) PC9 cells were treated with the indicated concentrations of VNR, CDDP, or 5-FU for 24, 24 and $72 \mathrm{~h}$, respectively. The survival cell fraction is expressed as the percentage of optical density (\% OD) in reference to the OD of untreated cells using a 3-(4,5-dimethylhiazol-2-yl)-2,5-diphenyltetrazolium bromide (MTT) assay $72 \mathrm{~h}$ after the start of drug exposure. Data are means $\pm \mathrm{SD}$ of three separate experiments.

Figure 3. Effects of vinorelbine (VNR), cisplatin (CDDP), and 5-fluorouracil (5-FU) on epidermal growth factor receptor (EGFR) phosphorylation in PC9 cells. (A) PC9 cells were treated with the indicated concentrations of VNR for $24 \mathrm{~h}$ (upper panels), or $20 \mathrm{nM}$ VNR for the indicated time (lower panels). Total cellular protein $(1 \mathrm{mg}$ ) from cell lysate was immunoprecipitated using anti-EGFR antibody and subjected to a western blot analysis with anti-phosphotyrosine (p-EGFR, upper panel), and the membrane was stripped of bound antibodies and re-probed with anti-EGFR antibody (middle panel). Total cellular protein $(20 \mu \mathrm{g})$ of the same lysate was subjected to a western blot analysis with $\beta$-actin (lower panel). (B and C) PC9 cells were treated with the indicated concentrations of CDDP or 5-FU for $24 \mathrm{~h}$ and processed as described above.

the proliferation or survival of 1BR3-LR cells is dependent on EGFR-mediated signaling in low-serum condition.

We compared the growth inhibitory activities of VNR, 5-FU, and CDDP in 1BR3-LR cells between normal (10\%) and low $(0.5 \%)$ serum conditions, and we found that the cell growth inhibition by VNR was enhanced in the low-serum condition compared to that in the normal-serum condition (Fig. 4C). The sensitivity of 1BR3-LR cells to CDDP did not clearly differ
B

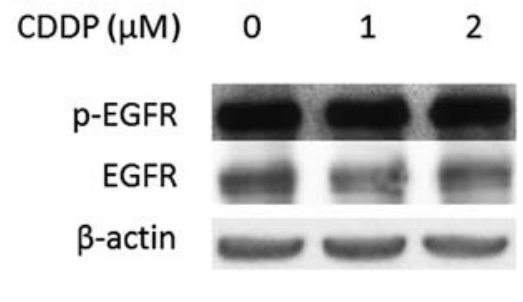

C

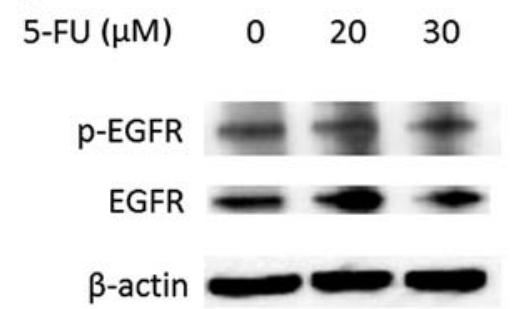

by serum concentration (Fig. 4D). In the low-serum condition, 1BR3-LR cells tended to be resistant to 5-FU-induced cell growth inhibition (Fig. 4E).

The effect of $\mathrm{Na}_{3} \mathrm{VO}_{4}$ on EGFR phosphorylation and gefitinib-and VNR-induced cell growth inhibition. To further test whether the EGFR dephosphorylation induced by VNR was related to anti-proliferative effect of VNR, we tested 

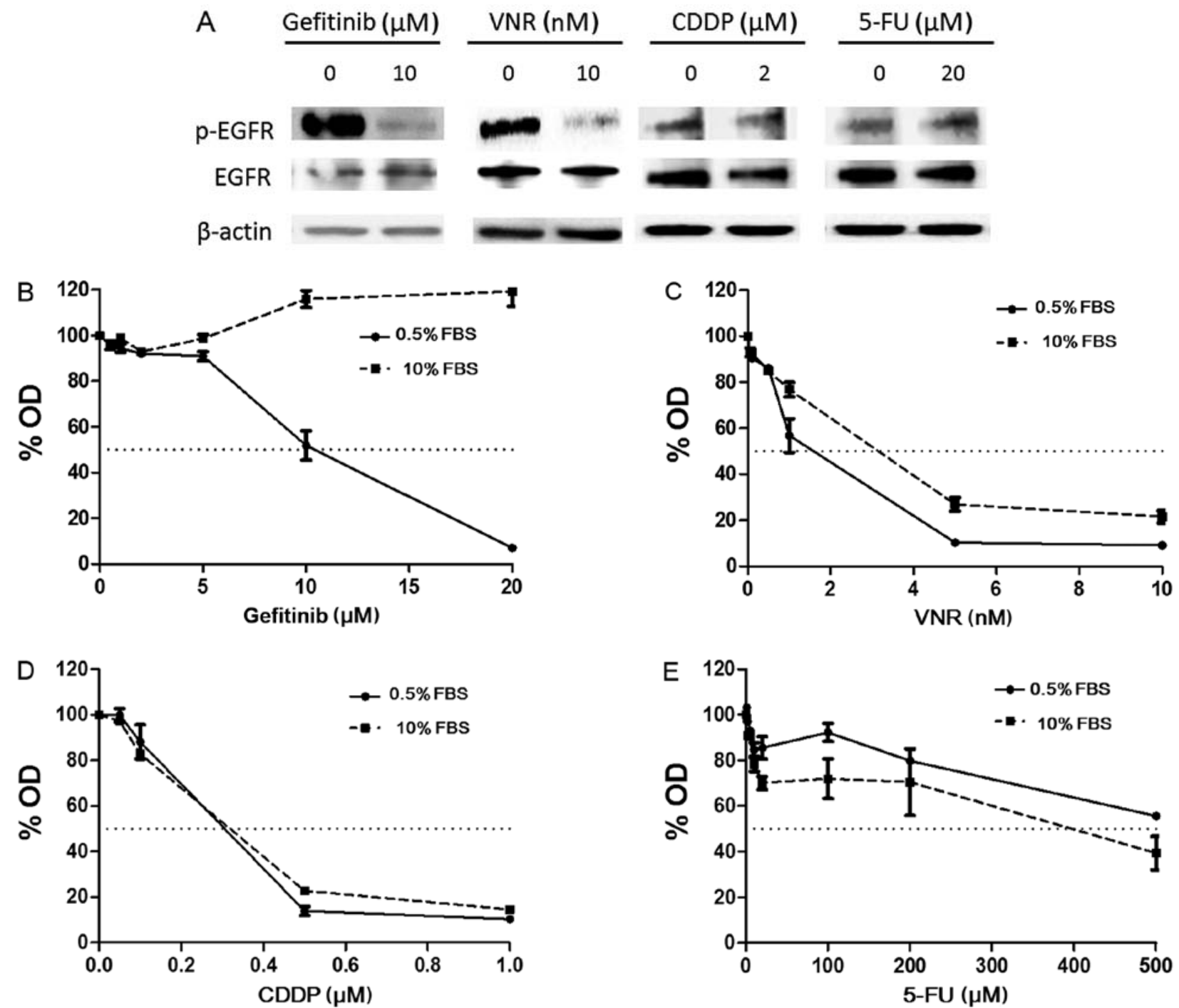

Figure 4. Effects of vinorelbine (VNR), cisplatin (CDDP), and 5-fluorouracil (5-FU) on epidermal growth factor receptor (EGFR) phosphorylation and cell growth inhibition in 1BR3-LR cells. (A) 1BR3-LR cells were treated with the indicated concentrations of gefitinib, VNR, CDDP, or 5-FU for $24 \mathrm{~h}$. Total cellular protein $(1 \mathrm{mg})$ from cell lysate was immunoprecipitated using anti-EGFR antibody and subjected to a western blot analysis with anti-phosphotyrosine (p-EGFR, upper panel), and the membrane was stripped of bound antibodies and re-probed with anti-EGFR antibody (middle panel). Total cellular protein (20 $\mu \mathrm{g})$ of the same lysate was subjected to a western blot analysis with $\beta$-actin (lower panel). (B-E) 1BR3-LR cells were treated with the indicated concentrations of gefitinib, VNR, CDDP, or 5-FU for $72 \mathrm{~h}$ in the medium containing $10 \%$ (solid line) or $0.5 \%$ (dotted line) fetal bovine serum (FBS). The survival cell fraction is expressed as the percentage of optical density (\% OD) in reference to the OD of the untreated cells in an 3-(4,5-dimethylhiazol-2-yl)-2,5-diphenyltetrazolium bromide (MTT) assay. Data are presented as means \pm SD of three separate experiments.

whether $\mathrm{Na}_{3} \mathrm{VO}_{4}$, an inhibitor of protein tyrosine phosphatases, can interfere with the gefitinib- or VNR-induced dephosphorylation of EGFR and affect the cell growth inhibition by gefitinib or VNR in PC9 cells. We treated PC9 cells with $50 \mathrm{nM}$ gefitinib or $20 \mathrm{nM}$ VNR in the presence or absence of $50 \mu \mathrm{M} \mathrm{Na} \mathrm{VO}_{4}$ for $24 \mathrm{~h}$ and then evaluated the EGFR phosphorylation. The EGFR dephosphorylation caused by gefitinib or VNR was clearly inhibited in the presence of $\mathrm{Na}_{3} \mathrm{VO}_{4}$ (Fig. 5A and B).

The cell growth inhibition of PC9 cells by gefitinib or VNR was compared in the presence or absence of $\mathrm{Na}_{3} \mathrm{VO}_{4}$. As shown in Fig. 5C and D, the cell growth inhibitory activity of both gefitinib and VNR was greatly interfered with by $\mathrm{Na}_{3} \mathrm{VO}_{4}$.

Synergistic cell growth inhibition by the combination of gefitinib or VNR with 5-FU in PC9 cells. In our previous study, the combination treatment of VNR and subsequent 5-FU synergistically inhibited cell growth in three NSCLC cell lines (18). In the present study, to reproduce this synergism and to clarify whether EGFR suppression by VNR is related to this interaction, we evaluated the combination effects using the CI and the simultaneous combination of gefitinib and 5-FU, or the sequential treatment of VNR followed by 5 -FU. Since gefitinib suppressed EGFR activity within $1 \mathrm{~h}$ in vitro (6), gefitinib and 5-FU were combined simultaneously.

We treated PC9 cells with the indicated concentrations of gefitinib +5 -FU for $72 \mathrm{~h}$ or VNR for $24 \mathrm{~h}$ and 5-FU for the following $72 \mathrm{~h}$, and we calculated the CI (Fig. 6). As shown in the Fig., the CI values for the combination of gefitinib and 5 -FU were all $<1.0$, indicating that this simultaneous combination showed synergistic cell growth inhibitory activity against PC9 cells. Similar results were achieved for sequential exposure to VNR followed by 5 -FU with $\mathrm{CI}<0.3$, which implied strong synergism (Fig. 6B). 
A
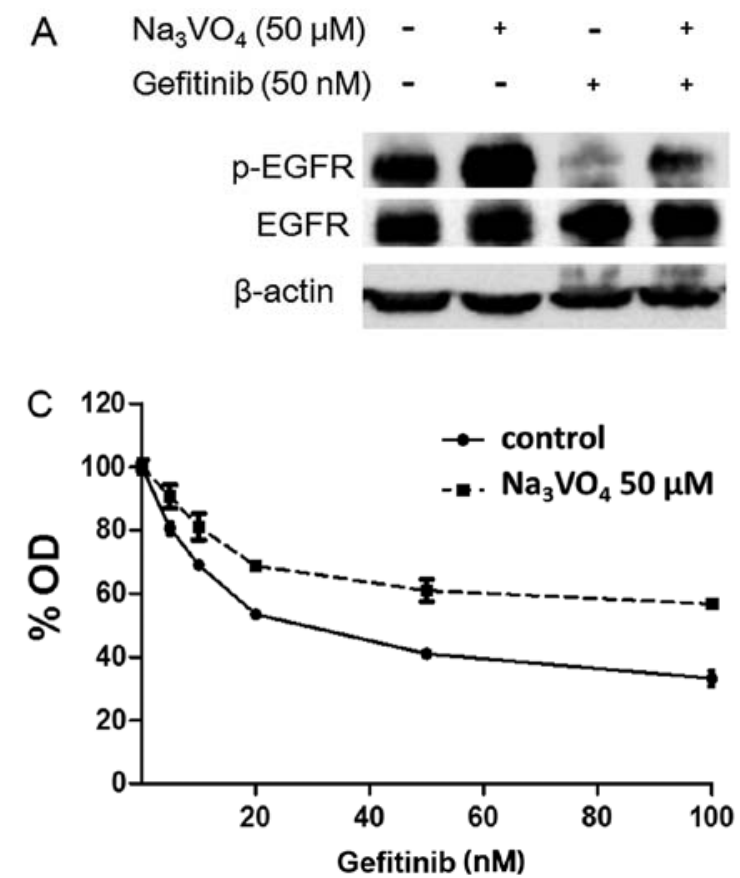
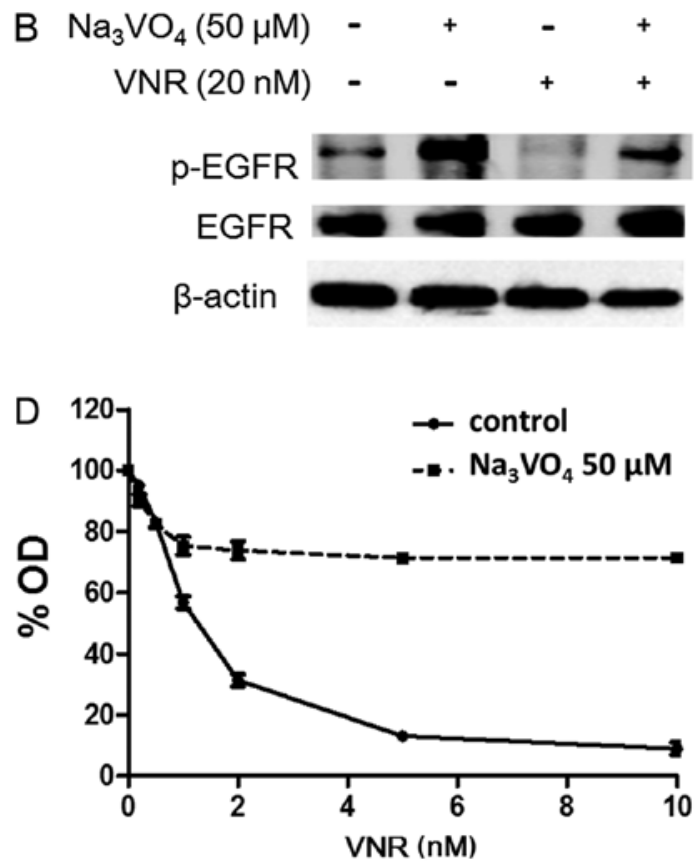

Figure 5. Effects of sodium orthovanadate $\left(\mathrm{Na}_{3} \mathrm{VO}_{4}\right)$ on epidermal growth factor receptor (EGFR) phosphorylation and the cell growth inhibition by gefitinib or vinorelbine (VNR) in PC9 cells. (A and B) PC9 cells were treated with $50 \mathrm{nM}$ gefitinib or $20 \mathrm{nM}$ VNR in the presence or absence of $50 \mu \mathrm{M} \mathrm{Na}_{3} \mathrm{VO}_{4}$ for $24 \mathrm{~h}$. Total cellular protein $(1 \mathrm{mg})$ from cell lysate was immunoprecipitated using anti-EGFR antibody and subjected to a western blot analysis with anti-phosphotyrosine (p-EGFR, upper panel), and the membrane was stripped of bound antibodies and re-probed with anti-EGFR antibody (middle panel). Total cellular protein $(20 \mu \mathrm{g})$ of the same lysate was subjected to a western blot analysis with $\beta$-actin (lower panel). (C and D) PC9 cells were treated with the indicated concentrations of gefitinib or VNR in the presence or absence of $50 \mu \mathrm{M} \mathrm{Na}_{3} \mathrm{VO}_{4}$ for $72 \mathrm{~h}$. The survival cell fraction is expressed as the \% OD in reference to the OD of the untreated cells in an 3-(4,5-dimethylhiazol-2-yl)-2,5-diphenyltetrazolium bromide (MTT) assay. Data are means \pm SD of three separate experiments.
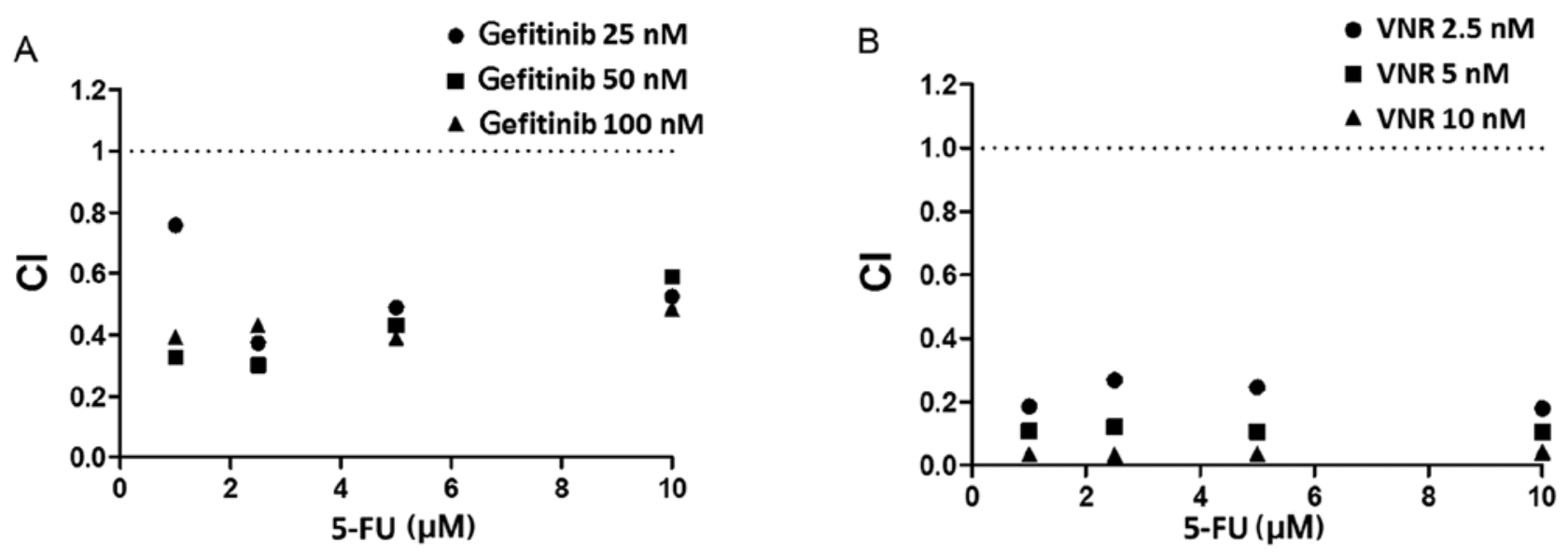

Figure 6. The synergistic cell growth inhibition by the combination of gefitinib or vinorelbine (VNR) with 5-fluorouracil (5-FU) in PC9 cells. (A) PC9 cells were treated with either a single agent or the simultaneous combination of 5-FU and gefitinib for $72 \mathrm{~h}$. (B) PC9 cells were treated with either a single agent or the sequential combination of VNR for $24 \mathrm{~h}$ and 5-FU for the next $72 \mathrm{~h}$. The viabilities of the cells were determined in an 3-(4,5-dimethylhiazol-2-yl)-2,5-diphenyltetrazolium bromide (MTT) assay. The combination index (CI) for each concentration of 5-FU was calculated by the Chou-Talalay method.

\section{Discussion}

The aim of this study was to evaluate whether the combination of VNR + DIF is a more effective treatment compared with the standard platinum-based chemotherapy in EGFR-mutated lung adenocarcinoma patients, and then to clarify the underlying mechanism by which VNR + DIF was efficacious in such patients. In the retrospective analysis, the PFS of the patients who received VNR + DIF chemotherapy was longer than that of the patients who received platinum-based chemotherapy. Using mutated EGFR-expressing cells, we found that VNR induced EGFR dephosphorylation and that this effect of VNR may be related to its cell growth inhibitory activity. We propose that EGFR inhibition by VNR may be one of the mechanisms of the synergistic effect by the sequential treatment of VNR and subsequent 5-FU. 
In this retrospective study, the characteristics of the patients who received VNR + DIF chemotherapy were not significantly different from those who received platinumbased chemotherapy. Nevertheless, the PFS of the VNR + DIF treatment group was significantly longer than that of the platinum-based chemotherapy group. The RR and DCR values of the VNR + DIF chemotherapy patients also tended to be better than those of the platinum-based chemotherapy patients, although the difference was not significant. These results suggest that the combination of VNR + DIF may be more effective than platinum-based chemotherapy, at least in terms of the antitumor effect in lung adenocarcinomas with EGFR-activating mutations.

Despite the significant difference in PFS, the OS of the present two regimen groups was not significantly different. Over one-quarter of the patients in each group crossed over to the other regimen as a later-line treatment. The comparison of OS was performed between small groups $(n=24$ for $\mathrm{VNR}+\mathrm{DIF}, \mathrm{n}=15$ for platinum), and thus the statistical power was low. We suspect that the lack of a significant difference in OS was due to these reasons. In a proportional hazard analysis performed in another study, we found that the application of the VNR + DIF combination but not platinum-based chemotherapy was a significant and independent factor to prolong survival in lung adenocarcinoma patients with $E G F R$ mutations (unpublished data). These results suggest that VNR + DIF chemotherapy may be superior to platinum-based chemotherapy in the treatment of lung adenocarcinoma patients with $E G F R$ mutations.

To clarify the mechanisms by which VNR + DIF chemotherapy was favorable in the treatment of EGFR-mutated lung adenocarcinoma, we focused on the effects of VNR and 5-FU on EGFR phosphorylation. In EGFR-mutated PC9 cells, VNR induced EGFR dephosphorylation 12-24 h after drug exposure at the concentration of $10 \mathrm{nM}$ or higher. In the treatment of NSCLC, when $20-30 \mathrm{mg} / \mathrm{m}^{2}$ of VNR is administered, a VNR concentration $>10 \mathrm{nM}$ is maintained in peripheral blood for 12-24 h (26). Thus, an EGFR-dephosphorylating concentration of VNR is clinically achievable.

The sufficiently cell growth-inhibiting and clinically relevant concentration of CDDP and 5-FU (27-29) did not affect the EGFR phosphorylation in PC9 cells. Our observation in terms of EGFR dephosphorylation by VNR is in accord with the result of a previous investigation. Wu et al reported that in esophageal cancer cells, the disruption of the microtubule network induced by microtubule-targeting drugs such as docetaxel and vincristine, another vinca-alkaloid, was associated with EGFR dephosphorylation and the subsequent inhibition of Akt and Erk (30). VNR is a semisynthetic vinca-alkaloid, a member of the family of microtubule-targeting drugs. Although the precise mechanism is still unknown, EGFR-suppressing activity may thus be a common property among taxanes and vinca-alkaloids.

To test whether the EGFR dephosphorylation induced by VNR is associated with its anti-proliferative effect, we took advantage of 1BR3-LR cells, which express an active form of EGFR. Parental 1BR3 cells do not express EGFR. Although we observed that 1BR3-LR cells were completely resistant to gefitinib in normal culture medium containing $10 \% \mathrm{FBS}$, gefitinib showed cell growth inhibition against 1BR3-LR cells in the medium containing $0.5 \%$ FBS. These results indicate that the growth or survival of 1BR3-LR cells is at least partially dependent on EGFR signaling in a low-serum condition.

We also found that the growth inhibition of 1BR3-LR cells by VNR was enhanced in the low-serum condition, although such changes of drug sensitivity were not observed in CDDP- or 5-FU-treated cells. These findings strongly support the interpretation that the enhanced sensitivity to VNR in the low-serum condition is not a non-specific effect but rather is due to the suppression of EGFR signaling, since both gefitinib and VNR (and not CDDP or 5-FU) suppressed EGFR phosphorylation.

This interpretation is further supported by our finding that $\mathrm{Na}_{3} \mathrm{VO}_{4}$ interfered with the EGFR dephosphorylation induced by gefitinib and VNR, and suppressed the cell growth inhibition by these agents in PC9 cells. Taken together, our results led us to conclude that VNR-induced EGFR dephosphorylation is associated with the anti-proliferative effect of VNR in lung adenocarcinoma cell lines harboring $E G F R$ mutations.

We found previously that the combination of VNR followed by 5-FU resulted in synergistic cell growth inhibition in three NSCLC cell lines (18). The synergism was also observed in PC9 cells harboring an EGFR mutation with the sequential treatment of VNR and then 5-FU. Therefore, although it still remains to be determined whether the EGFR suppression by VNR itself may lead to a better antitumor effect of VNR in EGFR-mutated lung adenocarcinoma, it is possible that this synergism also contributed to the favorable antitumor activity observed in patients treated with VNR + DIF.

In addition, as in an earlier study (31), the simultaneous combination of gefitinib and 5-FU showed synergistic cell growth inhibition in PC9 cells in the present study. Therefore, the synergism of VNR followed by 5-FU may be attributable, at least in part, to the EGFR-suppressing activity of VNR.

The important therapeutic target of 5-FU is thymidylate synthase (TS), and the downregulation of TS would be expected to enhance the cytotoxicity of 5-FU (32). EGFR signal transduction has been shown to be involved in the expression of $T S$ genes $(33,34)$, and in our previous study, VNR as well as gefitinib was shown to suppress TS expression (18). Thus, the decrease of TS caused by EGFR suppression may be a common mechanism of the synergism by the combination of VNR or gefitinib with 5-FU.

The identification of activating mutations of the EGFR gene in a subset of NSCLC patients led to a change in the treatment of the disease (6), and the presence of EGFR mutations is a predictive marker of response to EGFR-TKI $(3,4)$. It has been reported that the effect of cytotoxic chemotherapy is not different between patients with and without $E G F R$ mutations $(35,36)$. Thus, the cytotoxic agents for NSCLC patients with $E G F R$ mutations are not different from those used for $E G F R$ wild-type patients. To our knowledge, there has been no prospective study attempting to identify which agents or combination chemotherapy is specifically effective in EGFR-mutated NSCLC.

The identification of such cytotoxic agents or combination chemotherapy is expected to improve the survival of NSCLC 
patients harboring EGFR mutations. In the present study, we observed favorable PFS by the combination of VNR + DIF and the potential mechanism of this good treatment outcome. We propose that the combination chemotherapy of VNR and DIF can be a promising strategy for NSCLC patients harboring EGFR mutations. Since our observations were retrospective and experimental, there are several limitations. To establish the optimal VNR + DIF combination chemotherapy in NSCLC patients with EGFR mutations, we are performing a prospective phase II trial of this treatment targeting such patients.

In conclusion, the PFS afforded by the VNR + DIF combination treatment was significantly longer compared to that of platinum-based chemotherapy in lung adenocarcinoma patients with EGFR mutations. VNR suppressed EGFR phosphorylation in PC9 cells, and this activity may be related with cell growth inhibition of VNR, and the synergistic cell growth inhibition when VNR was combined with 5-FU. The combination chemotherapy of VNR + DIF may be a promising treatment for NSCLC patients with EGFR mutations.

\section{References}

1. Schiller JH, Harrington D, Belani CP, et al: Comparison of four chemotherapy regimens for advanced non-small-cell lung cancer. N Engl J Med 346: 92-98, 2002.

2. Ohe Y, Ohashi Y, Kubota K, et al: Randomized phase III study of cisplatin plus irinotecan versus carboplatin plus paclitaxel, cisplatin plus gemcitabine, and cisplatin plus vinorelbine for advanced non-small-cell lung cancer: Four-Arm Cooperative Study in Japan. Ann Oncol 18: 317-323, 2007.

3. Paez JG, Jänne PA, Lee JC, et al: EGFR mutations in lung cancer: correlation with clinical response to gefitinib therapy. Science 304: 1497-1500, 2004

4. Mitsudomi T and Yatabe Y: Mutations of the epidermal growth factor receptor gene and related genes as determinants of epidermal growth factor receptor tyrosine kinase inhibitors sensitivity in lung cancer. Cancer Sci 98: 1817-1824, 2007.

5. Nana-Sinkam SP and Powell CA: Molecular biology of lung cancer: diagnosis and management of lung cancer, 3rd ed: American College of Chest Physicians evidence-based clinical practice guidelines. Chest 143 (Suppl 5): e30S-e39S, 2013.

6. Lynch TJ, Bell DW, Sordella R, et al: Activating mutations in the epidermal growth factor receptor underlying responsiveness of non-small-cell lung cancer to gefitinib. N Engl J Med 350: 2129-2139, 2004.

7. Mitsudomi T, Morita S, Yatabe Y, et al: Gefitinib versus cisplatin plus docetaxel in patients with non-small-cell lung cancer harbouring mutations of the epidermal growth factor receptor (WJTOG3405): an open label, randomised phase 3 trial. Lancet Oncol 11: 121-128, 2010.

8. Maemondo M, Inoue A, Kobayashi K, et al: Gefitinib or chemotherapy for non-small-cell lung cancer with mutated EGFR. N Engl J Med 362: 2380-2388, 2010.

9. Okamoto I, Yoshioka H, Morita S, et al: Phase III trial comparing oral S-1 plus carboplatin with paclitaxel plus carboplatin in chemotherapy-naïve patients with advanced non-small-cell lung cancer: results of a west Japan oncology group study. J Clin Oncol 28: 5240-5246, 2010.

10. Hanna N, Shepherd FA, Fossella FV, et al: Randomized phase III trial of pemetrexed versus docetaxel in patients with non-small-cell lung cancer previously treated with chemotherapy. J Clin Oncol 22: 1589-1597, 2004.

11. Pujol JL, Barlesi F and Daurès JP: Should chemotherapy combinations for advanced non-small cell lung cancer be platinum-based? A meta-analysis of phase III randomized trials. Lung Cancer 51: 335-345, 2006.

12. Gridelli C: The ELVIS trial: a phase III study of single-agent vinorelbine as first-line treatment in elderly patients with advanced non-small cell lung cancer. Elderly Lung Cancer Vinorelbine Italian Study. Oncologist 6 (Suppl 1): S4-S7, 2001.
13. Butts CA, Ding K, Seymour L, et al: Randomized phase III trial of vinorelbine plus cisplatin compared with observation in completely resected stage IB and II non-small-cell lung cancer: updated survival analysis of JBR-10. J Clin Oncol 28: 29-34, 2010.

14. Dunant A, Pignon JP and Le Chevalier T: Adjuvant chemotherapy for non-small cell lung cancer: contribution of the International Adjuvant Lung Trial. Clin Cancer Res 11: 5017s-5021s, 2005.

15. Douillard JY, Rosell R, De Lena M, et al: Adjuvant vinorelbine plus cisplatin versus observation in patients with completely resected stage IB-IIIA non-small-cell lung cancer (Adjuvant Navelbine International Trialist Association [ANITA]): a randomised controlled trial. Lancet Oncol 7: 719-727, 2006.

16. Nakagawa M, Tanaka F, Tsubota N, Ohta M, Takao M and Wada H; West Japan Study Group for Lung Cancer Surgery: A randomized phase III trial of adjuvant chemotherapy with UFT for completely resected pathological stage I non-small-cell lung cancer: the West Japan Study Group for Lung Cancer Surgery (WJSG) - the 4th study. Ann Oncol 16: 75-80, 2005.

17. Kato H, Ichinose $\mathrm{Y}$, Ohta M, et al: A randomized trial of adjuvant chemotherapy with uracil-tegafur for adenocarcinoma of the lung. N Engl J Med 350: 1713-1721, 2004.

18. Matsumoto S, Igishi T, Hashimoto K, etal: Schedule-dependent synergism of vinorelbine and 5-fluorouracil/UFT against non-small cell lung cancer. Int J Oncol 25: 1311-1318, 2004.

19. Igishi T, Shigeoka Y, Yasuda K, et al: UFT plus vinorelbine in advanced non-small cell lung cancer: a phase I and an elderly patient-directed phase II study. J Thorac Oncol 4: 376-382, 2009.

20. Kodani M, Kinoshita N, Ueda Y, Suyama H, Sumikawa T, Makino H, Kurai J, Matsumoto S, Igishi T and Shimizu E: Phase II study of S-1 and vinorelbine in patients with advanced non-small cell lung cancer. Eur J Cancer 47 (Suppl 1): S620, 2011.

21. Mok TS, Wu YL, Thongprasert S, et al: Gefitinib or carboplatin-paclitaxel in pulmonary adenocarcinoma. N Engl J Med 361: 947-957, 2009.

22. Eisenhauer EA, Therasse P, Bogaerts J, et al: New response evaluation criteria in solid tumours: revised RECIST guideline (version 1.1). Eur J Cancer 45: 228-247, 2009.

23. Takata M, Chikumi H, Miyake N, et al: Lack of AKT activation in lung cancer cells with EGFR mutation is a novel marker of cetuximab sensitivity. Cancer Biol Ther 13: 369-378, 2012.

24. Das AK, Chen BP, Story MD, Sato M, Minna JD, Chen DJ and Nirodi CS: Somatic mutations in the tyrosine kinase domain of epidermal growth factor receptor (EGFR) abrogate EGFR-mediated radioprotection in non-small cell lung carcinoma. Cancer Res 67: 5267-5274, 2007.

25. Chou TC and Talalay P: Quantitative analysis of dose-effect relationships: the combined effects of multiple drugs or enzyme inhibitors. Adv Enzyme Regul 22: 27-55, 1984.

26. Khayat D, Rixe O, Brunet R, et al: Pharmacokinetic linearity of i.v. vinorelbine from an intra-patient dose escalation study design. Cancer Chemother Pharmacol 54: 193-205, 2004.

27. Dickgreber NJ, Fink TH, Latz JE, Hossain AM, Musib LC and Thomas M: Phase I and pharmacokinetic study of pemetrexed plus cisplatin in chemonaive patients with locally advanced or metastatic malignant pleural mesothelioma or non-small cell lung cancer. Clin Cancer Res 15: 382-389, 2009.

28. Hirata K, Horikoshi N, Aiba K, et al: Pharmacokinetic study of S-1, a novel oral fluorouracil antitumor drug. Clin Cancer Res 5: 2000-2005, 1999.

29. Muggia FM, Wu X, Spicer D, et al: Phase I and pharmacokinetic study of oral UFT, a combination of the 5-fluorouracil prodrug tegafur and uracil. Clin Cancer Res 2: 1461-1467, 1996.

30. Wu X, Sooman L, Lennartsson J, Bergström S, Bergqvist M, Gullbo J and Ekman S: Microtubule inhibition causes epidermal growth factor receptor inactivation in oesophageal cancer cells. Int J Oncol 42: 297-304, 2013.

31. Okabe T, Okamoto I, Tsukioka S, et al: Synergistic antitumor effect of S-1 and the epidermal growth factor receptor inhibitor gefitinib in non-small cell lung cancer cell lines: role of gefitinib-induced down-regulation of thymidylate synthase. Mol Cancer Ther 7: 599-606, 2008.

32. Wada Y, Yoshida K, Suzuki T, et al: Synergistic effects of docetaxel and S-1 by modulating the expression of metabolic enzymes of 5-fluorouracil in human gastric cancer cell lines. Int J Cancer 119: 783-791, 2006. 
33. Hanada N, Lo HW, Day CP, Pan Y, Nakajima Y and Hung MC: Co-regulation of B-Myb expression by E2F1 and EGF receptor. Mol Carcinog 45: 10-17, 2006.

34. Ginsberg D: EGFR signaling inhibits E2F1-induced apoptosis in vivo: implications for cancer therapy. Sci STKE 2007: pe4, 2007.

35. Lee KH, Han SW, Hwang PG, et al: Epidermal growth factor receptor mutations and response to chemotherapy in patients with non-small-cell lung cancer. Jpn J Clin Oncol 36: 344-350, 2006.
36. Takano T, Fukui T, Ohe Y, et al: EGFR mutations predict survival benefit from gefitinib in patients with advanced lung adenocarcinoma: a historical comparison of patients treated before and after gefitinib approval in Japan. J Clin Oncol 26: 5589-5595, 2008. 